\title{
Research on the Law and Prediction of Ground Settlement by Shield Tunneling Construction in Ningbo Rail Transit
}

\author{
Chen Bin \\ Ningbo Rail Transit Project Construction Headquarter \\ Ningbo, China \\ chenbin.nb@163.com \\ Li Ming \\ The Second Harbor Engineering Company, China \\ Communication Construction Company \\ Wuhan, China \\ li911ming@126.com
}

\author{
Wang Wenjun \\ Ningbo Institute of Technology, Zhejiang University \\ Ningbo, China \\ wwjcumt@nit.net.cn \\ Wang Guanqiong \\ Ningbo Rail Transit Project Construction Headquarter \\ Ningbo, China \\ grace880701@163.com
}

\begin{abstract}
Ground settlement laws and its control measures attract comprehensive attention in urban rail transit construction, particularly in soft soil area with shield tunneling method. Phase 1 of No.1 rail transit project in Ningbo is constructed by earth pressure balance (EPB) tunneling methods. In this paper, the horizontal ground settlement caused by single tunnel construction is studied by site measurement results. Correlation analysis of tunnel depth, grouting quantity, cover earth thickness, construction parameters and maximum settlement value is conducted. In the end, measurement data are linear fitted by least square method. Compared Peck formula with the result, the parameter selection and its applicability in Ningbo district are discussed. The research shows that the maximum width value of horizontal influence area can be up to 60 meters owing to the soft soil layer. Widths of settlement tank have mostly ranged between 15 and 20 meters. The maximum surface settlement has great linear relationship with grouting quantity, driving speed of shield machine and torque of cutter. But the depth of the tunnel has weak interaction with maximum ground settlement. Abovementioned research findings can provide technical support and theoretical guidance for the following rail transit construction in Ningbo.
\end{abstract}

Keywords-Tunneling construction; rail transit; ground settlements; width of settlement tank; modified peck formula

\section{INTRODUCTION}

In coastal soft soil area, the driving of shield machine creates ground disturbance. Soil stress, water content, pore water pressure, elastic modulus, possion's ratio, strength and bearing capacity have been changed in and after construction process. These factors cause ground settlement and horizontal movement [1-2]. After that, a series of engineering disasters can be occurred, for instance, cracking and deformation of the surrounding buildings, road damage, pipeline fracture, etc. Therefore, scholars have focused on reducing harmful disturbance in tunnel construction, ground settlement prediction, protection of surrounding buildings and roads. Recently, studies have been carried out in the field such as ground settlement law, changes of soil properties, building damages, etc [3-7].

Ningbo is a typical coastal district with soft soil. Silt and silt clay is widely distributed in soil layers, with high water content and compressibility, low strength and permeability. The above problems posing a challenge to settlement control in tunnel construction. In the preliminary phase of Ningbo Rail Transit Project, whether in design or construction, challenges exist due to lack of experiences in surrounding environment influence and settlement control. In this paper, take the case of No.1 rail transit construction in Ningbo to analyze the ground settlement data. Factor influences analysis and settlement behavior are conducted. Based on the fitting analysis, ground settlement prediction and corresponding parameters research is carried out. By further study on engineering properties of soft soils and environmental effects, we attempt to use feedback to guide the optimal design of subsequent engineering and its construction safety.

\section{SOIL LAYERS AND PROPERTIES}

Phase 1 of Ningbo rail transit construction was designed as double tunnel. Inside diameters: 5500 millimeters. Outside diameters: 6200 millimeters. The two lines successively under constructed by two earth pressure balance (EPB) shield machines. According to the statistics along the tunnel, depths of tunnel ranged between 6 and 22 meters, which largely depend upon the changed layers. Take Ximenkou-Gulou interval as an example, the depth of tunnel ranges between 9.2 and 16.5 meters. The spacing of two parallel lines ranges from 11.8 to 14.6 meters. Underground soil layers include gray silt clay, mucky silty clay, clayey silt, grey silty clay silt, grey silty clay, silty clay, clay and hard pan. The main properties of soil layers see TABLE I. 
TABLE I. Physical and mechanical properties of main soil layers

\begin{tabular}{|c|c|c|c|c|c|}
\hline \multirow{2}{*}{$\begin{array}{l}\text { Layer } \\
\text { No. }\end{array}$} & \multirow[b]{2}{*}{ Layer name } & \multirow{2}{*}{$\begin{array}{c}\text { Moisture } \\
\text { content } \\
/ \%\end{array}$} & \multirow{2}{*}{$\begin{array}{l}\text { Compression } \\
\text { modulus } \\
/ \mathrm{MPa}\end{array}$} & \multicolumn{2}{|c|}{$\begin{array}{c}\text { Consolidated quick } \\
\text { shear index }\end{array}$} \\
\hline & & & & $\begin{array}{c}\text { Cohesion } \\
/ \mathrm{kPa}\end{array}$ & $\begin{array}{l}\text { Internal } \\
\text { friction } \\
\text { angle } /^{\circ}\end{array}$ \\
\hline (2) $2-2$ & Silt clay & 45.9 & 2.62 & 15.9 & 9.7 \\
\hline (2) 3 & $\begin{array}{l}\text { Mucky silty } \\
\text { clay }\end{array}$ & 37.8 & 3.12 & 18.5 & 11.2 \\
\hline (3) 1 & Clayey silt & 29.6 & 6.9 & 6.5 & 24.6 \\
\hline (3) 2 & Silty clay & 32.6 & 3.63 & 15.5 & 13.2 \\
\hline (4) $1-1$ & $\begin{array}{l}\text { Mucky silty } \\
\text { clay }\end{array}$ & 40.6 & 3.0 & 15.9 & 9.4 \\
\hline (4) $1-2$ & Silt clay & 33.0 & 3.93 & 19.6 & 12.5 \\
\hline (4) 2 & Clay & 42.3 & 2.96 & 22.8 & 10.9 \\
\hline (5) 1 & Silt clay & 28.3 & 6.59 & 40.2 & 17.3 \\
\hline
\end{tabular}

\section{ANALYSIS OF GROUND SETTLEMENT}

\section{A. Monitoring Points Lay-out}

In the process of tunnel construction, the measuring points are placed unequally along the tunnel wall no more than 30 meters. Measuring points lay-out is shown in Fig. 1.

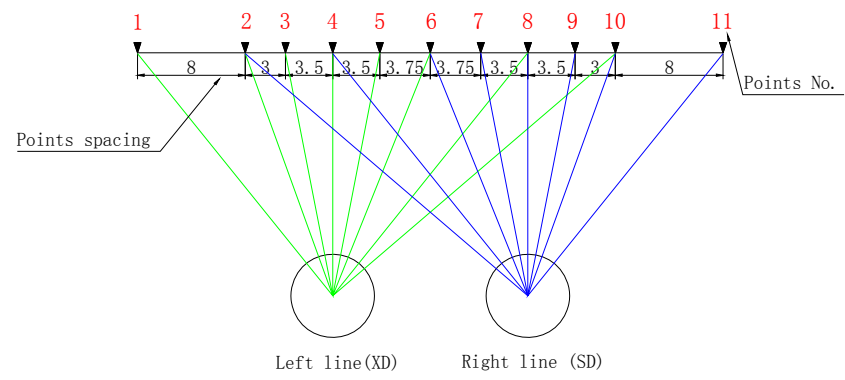

Figure 1. Lay-out of monitoring points for ground settlement

\section{B. Horizontal ground settlement curves}

The ground settlement of cross sections in XimenkouGulou interval is analyzed. Five stages of horizontal settlement curves are presented considering only single tunnel. As follows:

1) $5 \mathrm{D}$ approaching, it means the distance between excavation face and monitoring cross section is 5 times the diameter of the shield (5D).

2) 1D 2D approaching, it means the distance between excavation face and monitoring cross section is 1 to 2 times the diameter of the shield (1D 2D).

3) 0 distance, it means the monitoring cross section is closed to the excavation face.

4) $5 \mathrm{D}$ passed, it means the excavation face has passed the monitoring cross section about 5 times the diameter of the shield (5D).

5) $10 \mathrm{D}$ passed, it means the excavation face has passed the monitoring cross section about 10 times the diameter of the shield (10D).

Fig. 2 shows ground settlement curves of five typical monitoring cross sections.
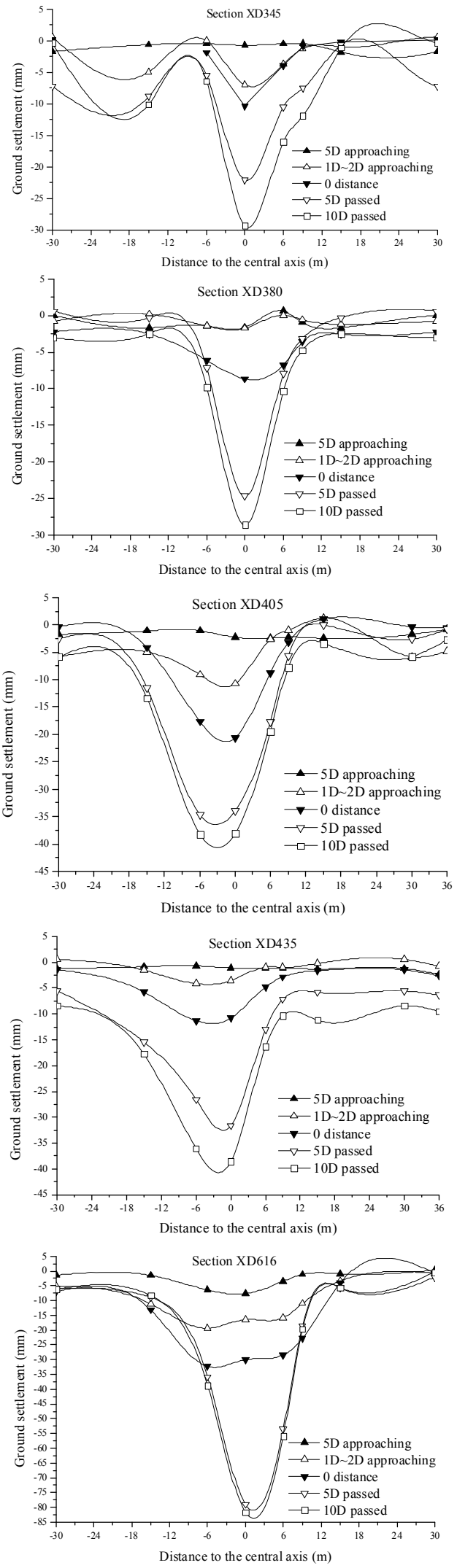

Figure 2. Ground settlement curves of typical monitoring cross sections 


\section{Horizontal ground settlement characteristics}

According to the monitoring data analysis of cross section of Ximenkou-Gulou interval, it is observed that,

1) Along with the driving of the shield, the width of horizontal settlement tank in the same cross section remains unchanged, but with bigger slope. Before the shield approaching the monitoring cross section, in 1D 2D approaching stage, evident horizontal settlement tank produced.

2) The maximum ground settlement locates in the central axis. Meanwhile, the more distance between the central axis and monitoring point, the smaller settlement. In practical engineering, maximum settlement has the deviation in several cross sections owing to the uneven grouting, orientation error, uneven distribution of soil layers, etc.

3) The horizontal effect region of single tunnel can be up to 60 meters, but most of the settlement tank widths are within 20 meters.

Gan Tao (2011) analyzed measured settlement of Fuming Road-Shiji Road interval in Ningbo and proposed that the settlement tank in Ningbo mainly ranged from 8 meters to 16 meters. Most of the settlement tanks widths value near 12 meters. The main settlement zone and widths of settlement tanks are different from typical regions in China, except for Shanghai city. The typical influence scope is left or right 15 meters distance in Shanghai. Large settlement occurs within 9 meters. The ground settlement is less than 10 millimeters without any influence when it is far away from the tunnel [8].

\section{INFLUENCE FACTORS OF MAXIMUM SETTLEMENT}

According to the measured settlement data on Ningbo No.1 rail transit project, statistical analysis is conducted in some aspects as maximum ground settlement, depth of tunnel, grouting quantity, cover earth thickness and construction parameters. The results are shown in Fig. 3 Fig. 6 .

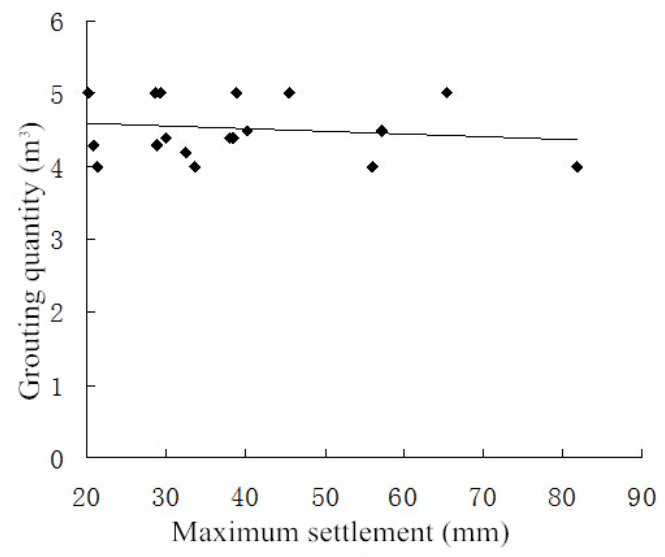

Figure 3. Relationship of maximum settlement and grouting quantity

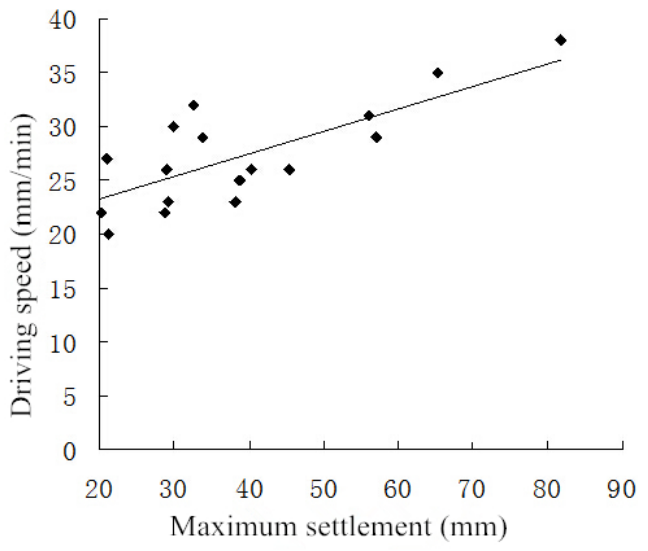

Figure 4. Relationship of maximum settlement and driving speed

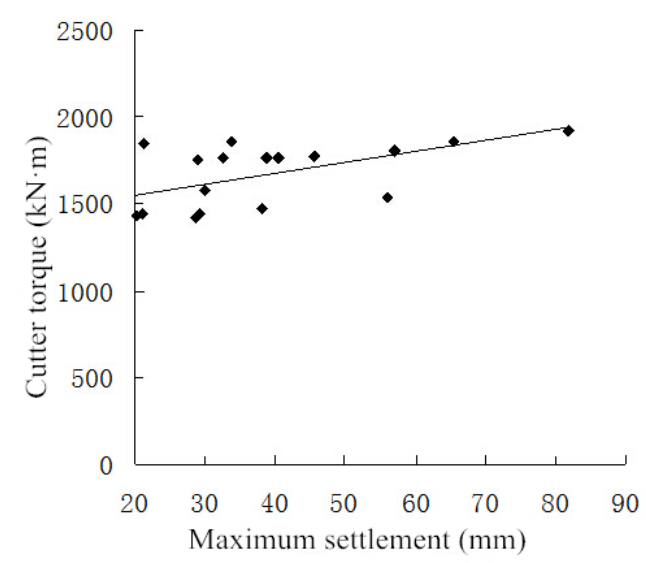

Figure 5. Relationship of maximum settlement and cutter torque

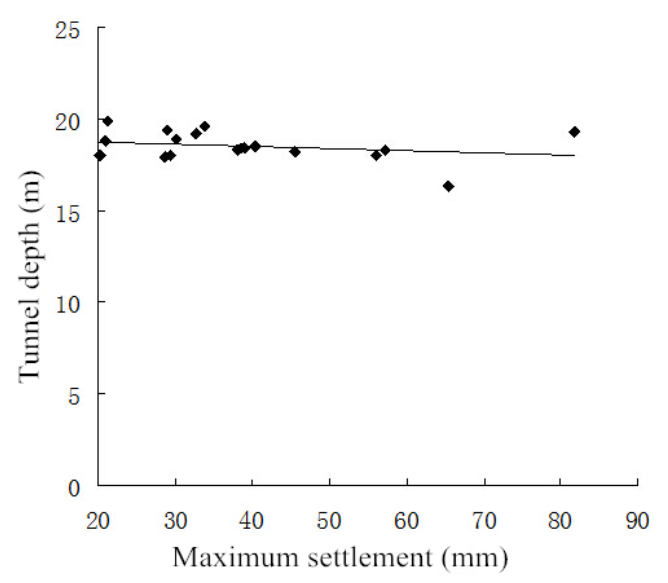

Figure 6. Relationship of maximum settlement and depth of tunnel

From Fig. 3 Fig. 6, it can be concluded that,

1) The more grouting quantity, the less ground settlement. In soft soil layers, sufficient grouting quantity 
can make up for losses caused by tunnel excavation, controlling the subsidence effectively.

2) Driving speed of shield has great impact on ground settlement. Meanwhile, the speed is limited by soil layers, facility condition, construction level, etc. The disturbance can be reduced at a lower driving speed if the construction period is controlled well.

3) The larger cutter torque, the more ground settlement. So the cutter torque shows great influence on the ground subsidence.

4) The maximum subsidence and depth of tunnel show weak linear relationship. Except the depth factor, the subsidence value is closely related to thickness and properties of soil layers. Therefore, the law of maximum settlement and depth of the tunnel is not obvious.

\section{PREDICTION OF GROUND SETTLEMENT}

Peck formula is widely used in empirical formula prediction caused by urban tunnel construction [9]. According to the horizontal subsidence measurement data analysis, we modified the parameters of Peck formula and make the evaluation of its application in Ningbo.

On the basis of measured subsidence data, after obtaining $\mathrm{K}$ value and ground loss ratio $\mathrm{V}_{1}$ by Peck curve fitting, we suggest that $\mathrm{K}$ value should be $0.6 \sim 0.9$ (preferably 0.75), where $\mathrm{K}$ is the width factor of Ximenkou-Gulou interval in Ningbo. The ground loss ratio $\mathrm{V}_{1}$ should be $0.5 \% \sim 2.5 \%$ (preferably $1.5 \%$ ). The comparative analysis of measured settlement curves, Gaussian fitting curve and Peck formula prediction curves show that the correlation index can be up to 0.90 with good fitting features. Respecting the above-mentioned facts, it is practicable to fit ground settlement tank. After all the unmodified value in prediction curves cannot reflect the measure settlement results. As well, we need to modify the value of $\mathrm{K}$ and $\mathrm{V}_{1}$ to make the prediction more precise.

Currently, many scholars have studied the application of Peck formula in different regions. Meanwhile, some modifications and expansions are conducted on the basis of Peck's theory. For instance, $\alpha$ and $\beta$ are introduced which represent correction factor of maximum settlement and settlement width, respectively [10-12]. The mentioned two factors are determined based on the local soil conditions.

The modified Peck formula is written as follows,

$$
S(x)=\alpha S_{\max } * \exp \left(-\frac{x^{2}}{2(\beta i)^{2}}\right)
$$

Which $\alpha$ is the correction factor of maximum ground subsidence, $\beta$ is the correction factor of settlement width, $\mathrm{S}_{\max }$ is the maximum settlement value predicted by Peck formula, $\mathrm{i}$ is the settlement tank width predicted by Peck formula.

The above modified Peck formula can be transformed into linear function as follows.

$$
\ln S(x)=\ln \left(\alpha S_{\max }\right)+\left(-\frac{x^{2}}{2(\beta i)^{2}}\right)
$$

From the regression curve, which can be written as follows,

$$
S(x)=\exp (\hat{a}) \exp \left(-\frac{x^{2}}{2} \hat{b}\right)
$$

We will obtain,

$$
\ln S(x)=\ln (\alpha S \max )+\left(-\frac{x^{2}}{2(\beta i)^{2}}\right)=\hat{a}+\left(-\frac{x^{2}}{2} \hat{b}\right)
$$
follows,

By further operation, equations are obtained as

$$
\alpha=\frac{\exp (\hat{a})}{S_{\max }}, \quad \beta=\frac{\sqrt{\frac{1}{\hat{b}}}}{i}
$$

On the above deducing process, according the horizontal ground subsidence measure data of 50 cross sections in Ximenkou-Gulou interval, statistical analysis of correctional parameters is conducted.

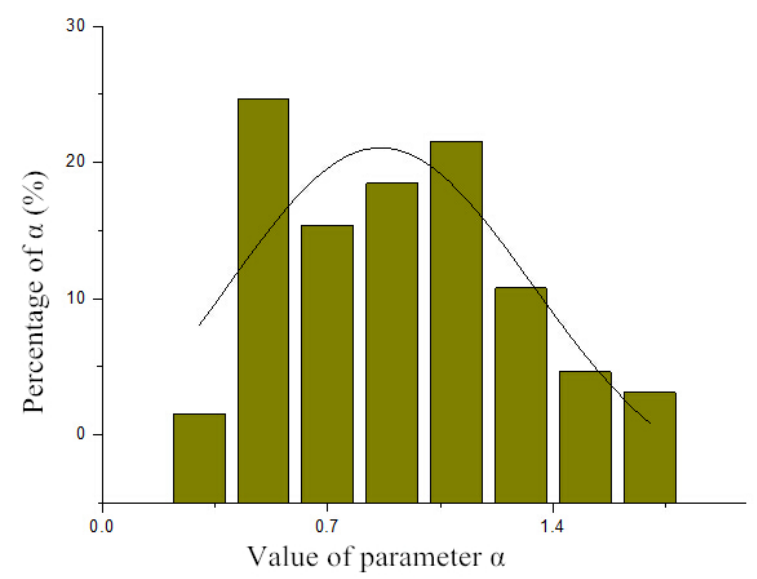

Figure 7. Statistic histogram of parameter $\alpha$

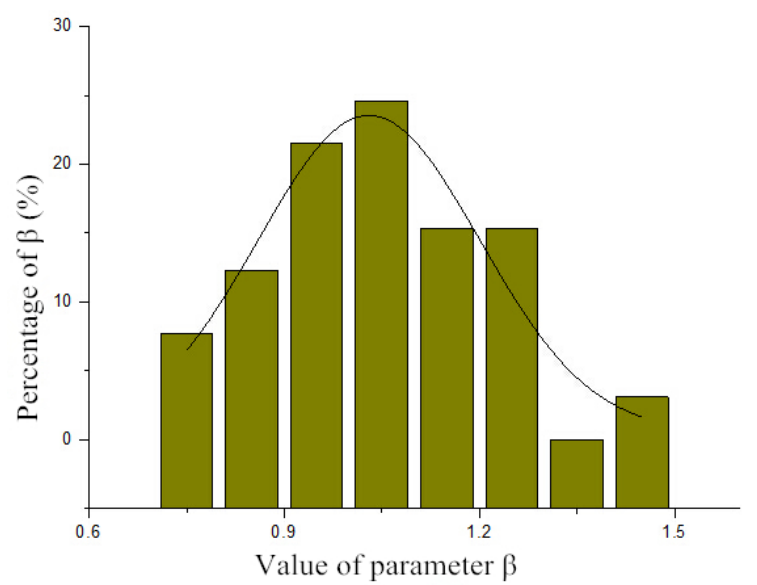

Figure 8. Statistic histogram of parameter $\beta$

As it can be seen from Fig. 7 and Fig. 8, the parameter $\alpha$ mainly in the ranges from 0.4 to 1.4 , around $70 \%$ of the total. The parameter $\beta$ ranges from 0.8 to 1.3 , around $90 \%$ of the total. Thus, for Ximenkou-Gulou interval, we set up the Peck prediction formula by using probability statistics and least-squares fitting method. The modified parameters $\alpha$ and $\beta$ in Peck prediction formula, range from 0.4 to $1.4,0.8$ to 1.3 , respectively. 


\section{CONCLUSION}

(1) The single horizontal ground subsidence monitoring data show that, with the driving of shield, settlement tank of the same cross section remains unchanged but with bigger slope. Before the shield approaching the monitoring cross section, in 1D 2D approaching stage, evident horizontal settlement tank produced. The maximum ground settlement is located in the central axis. The horizontal effect region of single tunnel can be up to 60 meters, but most of the settlement tank widths are within 20 meters. The width of settlement tank is similar to Shanghai.

(2) Correlation analysis of maximum settlement value, tunnel depth, grouting quantity, cover earth thickness and construction parameters shows that the more grouting quantity, the less ground subsidence. With higher driving speed or larger cutter torque, the greater the ground settlement is. The law of maximum settlement and depth of the tunnel is not obvious.

(3) On the basis of measured subsidence data, after obtaining $\mathrm{K}$ value and ground loss ratio $\mathrm{V}_{1}$ by Peck curve fitting with least square method, we suggest that $K$ value preferably should be 0.75 . The ground loss ratio $\mathrm{V}_{1}$ should preferably be $1.5 \%$. The modified parameters $\alpha$ and $\beta$ in Peck prediction formula, range from 0.4 to $1.4,0.8$ to 1.3 , respectively. Also, the above value of parameters still needs more monitoring data in construction to be verified.

\section{ACKNOWLEDGEMENTS}

This research was supported by the Science and Technology Plan Projects of Ningbo (Grant No. 2011C51011). The authors wish to express their gratitude to the above financial support.

Correspondence should be addressed to Wenjun Wang; wwjcumt@nit.net.cn

\section{REFERENCES}

[1] Yi H, Sun J. Mechanism analysis of disturbance caused by shield tunnelling on soft clays [J]. Journal of Tongji University, 2000, 28(3): 277-281.

[2] Zhang Y, Yin Z, Xu Y. Analysis of three-dimensional ground surface deformations due to shield tunnel [J]. Chinese Journal of Rock Mechanics and Engineering, 2002, 21(3): 388-392.

[3] Loganathan N, Poulos H G. Analytical prediction for tunnelinginduced ground movements in clays [J]. Journal of Geotechnical and Geoenvironmental Engineering, 1998, 124(9): 846-856.

[4] Selby A R. Tunnelling in soils - ground movements, and damage to buildings in Workington, UK $[\mathrm{J}]$. Geotechnical \& Geological Engineering, 1999, 17(3-4): 351-371.

[5] Bobet A. Analytical solutions for shallow tunnels in saturated ground [J]. Journal of Engineering Mechanics, 2001, 127(12): 1258-1266.

[6] Chou W I, Bobet A. Predictions of ground deformations in shallow tunnels in clay $[\mathrm{J}]$. Tunnelling and Underground Space Technology, 2002, 17(1): 3-19.

[7] Zhang Z, Zhang M. Deformation prediction of subway tunnel induced by EPB shield in soft clay during above and down overlapped traversing process and its construction control [J]. Chinese Journal of Rock Mechanics and Engineering, 2013, 32(S2): 3428-3439.

[8] Gan T. Study on the law of ground settlement with shield driven method in Ningbo area [D]. Zhejiang University, Hangzhou, 2012.

[9] Peck R B. Deep excavations and tunnelling in soft ground [C]//Proc. 7th int. conf. on SMFE. 1969: 225-290.

[10] Yao A, Zhao Q, Guan J, et al. Improvement of Peck formula in subway construction in Beijing [J]. Chinese Journal of Underground Space and Engineering, 2010, 4: 789-793.

[11] Hu B, Mo Y, Hu X, et al. Study of Peck equation applied to predict ground settlement induced by subway tunneling work in Wuhan $[\mathrm{J}]$. Geotechnical Investigation \& Surveying, 2012, 7: 6-10.

[12] Pan H, Jiang B, Huang T. An adaptability study of gaussian equation applied to predicting ground settlements induced by shield tunneling in Tianjin [J]. Science of Surveying and Mapping, 2010, 35(3): 53-55. 